\title{
Gender-based fatal effects of ambient air pollution
}

\author{
Camilla Mattiuzzi ${ }^{1} \cdot$ Giuseppe Lippi $^{2}$
}

Received: 15 August 2019 / Accepted: 3 February 2020 / Published online: 6 February 2020

(C) Springer-Verlag GmbH Germany, part of Springer Nature 2020

We read with interest the recent article of Liu et al. (2019), who carried out a large analysis of deaths attributable to ambient air pollution in Northeastern China during 2014-2017, concluding that exposure to particulate matter (PM) was associated with mortality in women but not in men. With the aim to provide further insights on gender-based differences in mortality for atherosclerotic heart disease due to PM, we carried out an electronic search in the Global Health Data Exchange (GHDx) registry, a large database of health-related data maintained by the Institute for Health Metrics and Evaluation (Institute for Health Metrics and Evaluation 2019), using the keywords "particulate matter pollution" and "ischaemic heart disease," combined with the epidemiologic variables "deaths," "year" ("2017"), "sex" ("male" and "female"), and "location" ("global" and "China").

According to our search in the GDHx database, the worldwide deaths for ischemic heart disease (IHD) attributable to PM exposure could be estimated at 1.387 million $(0.810$ million in men and 0.577 women) in 2017, 0.292 million of which in China (21.1\%; 0.166 million in men and 0.126 million in women). Compared with the worldwide mortality for IHD, those attributable to PM exposure accounted for 0.810 / 4.904 million cases $(16.5 \%)$ in men and $0.577 / 4.026$ million cases $(14.3 \%)$ in women, respectively. Similar evidence could be found in China, whereby IHD mortality attributable to PM exposure accounted for $0.166 / 0.944$ million cases (17.6\%) in men and 0.126/0.806 million cases (15.6\%) in women, respectively. This estimations would actually translate into a risk of dying for IHD due to PM exposure that is $\sim 18 \%$ higher in men than in women around the world (odds ratio, 1.18; $95 \%$ confidence interval, $1.18-1.19 ; p<0.001$ ), and that is similarly $\sim 16 \%$ higher in the male sex in China (odds ratio, 1.16; 95 confidence interval, $1.15-1.17 ; p<0.001$ ).

Although some peculiar variations may be seen on local basis, as recently shown by Liu et al. (2019), our analysis on the GDHx database suggests that the cumulative gender-based fatal effects of ambient PM exposure may be higher in men that in women, both on a nationwide basis in China and around the world.

\section{Compliance with ethical standards}

Conflict of interest The authors declare that they have no conflicts of interest.

\section{References}

Institute for Health Metrics and Evaluation (2019). Global Health Data Exchange. Available from: http://ghdx.healthdata.org/gbd-resultstool. Last accessed: August 6, 2019

Liu G, Sun B, Yu L, Chen J, Han B, Liu B, Chen J (2019) Short-term exposure to ambient air pollution and daily atherosclerotic heart disease mortality in a cool climate. Environ Sci Pollut Res Int 26: 23603-23614

Publisher's note Springer Nature remains neutral with regard to jurisdictional claims in published maps and institutional affiliations.

Responsible editor: Philippe Garrigues

Giuseppe Lippi

giuseppe.lippi@univr.it

1 Service of Clinical Governance, Provincial Agency for Social and Sanitary Services, Trento, Italy

2 Section of Clinical Biochemistry, University of Verona, Piazzale LA Scuro, 37134 Verona, Italy 